\title{
Effects of Conjugated Linoleic Acid on Anaphylaxis and Allergic Pruritus
}

\author{
Kyoko Ishiguro, ${ }^{*, a}$ Hisae Oku, ${ }^{a}$ Akiko Suttani, ${ }^{b}$ and Yoshikuni Yamamoto ${ }^{b}$ \\ ${ }^{a}$ School of Pharmaceutical Sciences, Mukogawa Women's University; 11-68 Koshien, Kyuban-cho, Nishinomiya \\ 663-8179, Japan: and ${ }^{b}$ Yamamoto Perfumery Co., Ltd.; 1-3-6 Kitakyuhoji-machi, Chuo-ku, Osaka 541-0057, Japan. \\ Received June 5, 2002; accepted September 2, 2002
}

\begin{abstract}
The effects of conjugated linoleic acid (CLA) against anaphylaxis and allergic pruritus were investigated using a in vivo assay. Inhibitory effects of CLA were observed on the immediate (type 1) hypersensitivity reaction, with CLA significantly suppressing the decrease in blood pressure (BP) and blood flow (BF) induced by the hen egg-white lysozyme (HEL)-anaphylactic reaction in ddY mice. After oral administration, CLA showed antipruritic activity, with significant inhibition of scratching behavior induced by compound 48/80 (COM), a histaminerelease agent. When painted onto the skin, CLA also inhibited COM, platelet-activating factor, and protease-induced scratching behavior, and COM-induced vasodilation of the skin. CLA offers promise as a drug for the treatment of allergic and inflammatory pruritus not only as an oral but also a topical agent. The present findings demonstrate that CLA can be effective for the prevention and treatment of allergic disease with severe pruritus.
\end{abstract}

Key words conjugated linoleic acid (CLA); antipruritus; antiallergy; antianaphylaxis; IgE

Conjugated linoleic acid (CLA) is the fatty acid group of compounds with conjugated double bonds in the intermolecule of linoleic acid. CLA was discovered by Kepler et al. in 1966. ${ }^{1)}$ It has been described as an anticarcinogenic agent in grilled ground beef. ${ }^{2)}$ Recently, CLA has gained explosive popularity with athletes and body builders in the U.S.A. based on reports of body fat reduction and lean body mass enhancement attributed to it. ${ }^{3)}$ CLA exerts diverse physiological actions against carcinogenesis, ${ }^{4)}$ arteriosclerosis, ${ }^{5)}$ diabetes, ${ }^{6}$ and cardiovascular disease. ${ }^{7}$ The immune system is also affected by CLA. CLA modulates certain aspects of immune defense, including increased lymphocyte ${ }^{8)}$ blastogenesis, macrophage phagocytes, ${ }^{9}$ and lymphocyte proliferation. ${ }^{10)}$ On the other hand, in the superfluous immune response, CLA increases the production of $\operatorname{IgA}$ and IgG, promoting the allergic response through their reduction, while reducing $\operatorname{IgE}$ by promoting the allergic response through a superfluous increase in lymphocytes. ${ }^{11)}$ CLA was also found to stimulate moderate production ${ }^{12)}$ of arachidonic acid and arachidonate-derived eicosanoid, including COX-2 activity or expression. ${ }^{13)}$ CLA inhibits the release of cytokines, ${ }^{14)}$ histamine, ${ }^{15)}$ and prostaglandin- $\mathrm{E}_{2}\left(\mathrm{PGE}_{2}\right)^{16)}$ from immune cells.

These reports led us to expect that CLA would inhibit the anaphylaxis (type I hypersensitivity reaction) and allergic pruritus by affecting chemical mediators. This paper describes the inhibitory effects of CLA against anaphylaxis using a blood pressure (BP) ${ }^{17)}$ or blood flow $(\mathrm{BF})^{18)}$ monitoring assay system and against allergic pruritus using a scratching (itch-associated response) measuring assay system. ${ }^{19)}$

\section{MATERIALS AND METHODS}

Materials CLA ( $75 \%$ purity) was purchased from Natural Co., Ltd. Other agents were obtained as follows: compound 48/80 (COM), Sigma; platelet activating factor (PAF), Funakoshi Co., Ltd.; bradykinin (BK), Peptide Institute Inc.; disodium cromoglycate (DSCG), Cascade Biochem Ltd. Inc.; carboxymethyl cellulose sodium salt (CMC) and hen eggwhite lysozyme (HEL), Wako Pure Chemical Industries, Ltd.; Macrogol 200, Sanyo Chemical Industries, Ltd. protease (PA), Worthington Biochemical Co.; serotonin hy- drochloride (5-HT), Tokyo Kasei Kogyo Co., Ltd.; Freund's complete adjuvant, DIFCO; Evans blue, Nacalai Tesque Inc.

Animals Male ddY mice (SPF grade), 4 weeks old, and male Wistar ST rats (SPF grade), 11 weeks old, were obtained from Japan SLC (Shizuoka, Japan) and housed at $24 \pm 2{ }^{\circ} \mathrm{C}$ and $60 \pm 5 \%$ relative humidity. Food and water were available ad libitum.

Administration of CLA CLA was emulsified in $0.5 \%$ CMC for oral administration or in Macrogol 200 for topical application on mice or rats.

Assay for Antianaphylactic Activity against HEL-Induced Anaphylaxis The antianaphylactic activity was investigated as previously reported using $\mathrm{BP}^{17)}$ and $\mathrm{BF}^{18)}$ monitoring. Immunization with HEL was performed as previously described. ${ }^{17,18)}$ Male ddY mice 5 weeks of age were sensitized i.p. on day 0 with HEL $50 \mu \mathrm{g}$ emulsified in Freund's complete adjuvant. To provoke anaphylaxis, on day 9 each mouse was challenged i.v. with HEL $1 \mu \mathrm{g}$ in saline $30 \mu \mathrm{l}$ for BP monitoring or HEL $10 \mu \mathrm{g}$ in saline $30 \mu \mathrm{l}$ saline for BF monitoring. The change in systolic BP of the tail artery of anaesthetized mice was measured for 15 to $20 \mathrm{~min}$ after challenge (the time after challenge in which BP was the lowest) using a nondirect-type BP monitor (MK-1030, Muromachi Kikai Co., Ltd.). The change in BF of the tail venous microcirculation of the unanesthetized mouse was measured every $2 \mathrm{~min}$ for $30 \mathrm{~min}$ after challenge using a laser-Doppler blood flowmeter of the noncontact type (FLO-N1, Neuroscience). The baseline (normal) BP and BF were measured for $10 \mathrm{~min}$ before challenge. The results are expressed as the mean \pm S.E. of the percent of normal BP or BF of each mouse. As a control, CLA untreated mice were challenged with HEL alone. A dose of CLA $100 \mathrm{mg} / \mathrm{kg}$ was administered orally for 2 weeks (from $5 \mathrm{~d}$ before sensitization to the day of challenge).

Assay of Inhibitory Effects on Production of AntiHEL-IgE The quantity of IgE in the serum of HEL-sensitized mice was investigated as previously reported, ${ }^{20)}$ using a heterogenous passive cutaneous anaphylaxis (PCA) reaction. A dose of CLA $100 \mathrm{mg} / \mathrm{kg}$ was administered orally for 2 weeks (from $5 \mathrm{~d}$ before sensitization to the day of challenge).

Assay of Inhibitory Effects on Intradermal COM-Induced Vasodilation The inhibitory effects of CLA on in- 
tradermal COM-induced vasodilation were investigated as previously reported ${ }^{20)}$ in rat skin. COM $(10 \mu \mathrm{g} / \mathrm{ml})$ at a dose $50 \mu \mathrm{l}$ was intradermally injected into the shaved backs of rats. After $30 \mathrm{~min}$, the extent of extravasation of dye $(0.5 \%$ Evans blue) by vasodilation was compared with the untreated (control) and CLA-painted skin. CLA (75\% purity) $30 \mu \mathrm{l}$ was applied topically $1 \mathrm{~h}$ before injection with COM.

Assay of Antipruritic Activity against COM-Induced Scratching Behavior The antipruritic activity was measured using a previously reported method examine the incidence of scratching behavior. ${ }^{19)} \mathrm{COM} 3 \mathrm{mg} / \mathrm{kg}$ was injected subcutaneously into the base of the neck on the back of mice to provoke scratching behavior. As a control, CLA-untreated mice were injected with $\mathrm{COM}$ alone to examine the incidence of scratching behavior without PAF and PA. CLA 200 $\mathrm{mg} / \mathrm{kg}$ was administered orally 1 or $24 \mathrm{~h}$ before injection with COM. CLA $100 \mathrm{mg} / \mathrm{kg} / \mathrm{d}$ was repeatedly administered orally once daily for 2 weeks before the provoked scratching behavior. CLA $0.625,1.25$, or $2.5 \mathrm{mg} / 30 \mu \mathrm{l} / \mathrm{d}$ was repeatedly applied topically on the COM-injected site once daily for $5 \mathrm{~d}$. The incidences of scratching behavior on the whole body and the site injected with COM were counted for $20 \mathrm{~min}$.

Assay of Antipruritic Activity against PAF and PA-Induced Scratching Behavior The antipruritic activity of CLA was measured after PAF ( $1 \mu \mathrm{g} / \mathrm{kg}$ s.c.) or PA $(1 \mathrm{mg} / \mathrm{kg}$ s.c.) was injected into the base of the neck on the back of mice to provoke scratching behavior. As a control, CLA-untreated mice were injected with PAF or PA alone to determine the incidence of scratching behavior without PAF and PA. CLA $2.5 \mathrm{mg} / 30 \mu \mathrm{l}$ was applied topically to the PAF- and PA-injected sites of mice once daily for $5 \mathrm{~d}$. The incidences of scratching behavior at the PAF- and PA-injected sites of mice were counted for $20 \mathrm{~min}$.

Statistical Analysis Each value represents the mean \pm S.E. The data were evaluated by Student's $t$-test ( $n=3-7 /$ group).

\section{RESULTS}

Antianaphylactic Effects of CLA Using BP and BF Monitoring Methods Figure 1 shows that CLA $100 \mathrm{mg} / \mathrm{kg}$ significantly inhibited the BP decrease induced by anaphylaxis when administered orally before challenge. In addition, CLA significantly inhibited the decrease in BF in anaphylaxis when administered orally before challenge with HEL (Fig. 2). CLA alone did not change either the BP or BF of the unchallenged mice (data not shown). These results suggest that CLA has an antianaphylactic effect. However, CLA did not decrease the concentration of anti-HEL-IgE in the serum of HEL-sensitized mice (data not shown).

Inhibitory Effects of CLA on COM-Induced Vasodilation in Rat Skin The diameter of Evans blue-dyed spots in untreated and CLA-treated rat skin was $9.48 \pm 0.3 \mathrm{~mm}$ and $8.71 \pm 0.5 \mathrm{~mm}$, respectively. The diameter of blue-dyed spots reflects vasodilation (increase in vascular permeability) induced by allergic mediators. CLA significantly $(p<0.05, n=$ 3 rats) inhibited COM-induced vasodilation in rat skin.

Inhibitory Effects of CLA on Scratching Behavior in Mice Figure 3A shows that CLA $200 \mathrm{mg} / \mathrm{kg}$ significantly inhibited COM-induced scratching behavior when administered orally $24 \mathrm{~h}$ before the evoked scratching behavior. However, it was not effective when administered orally $1 \mathrm{~h}$ before

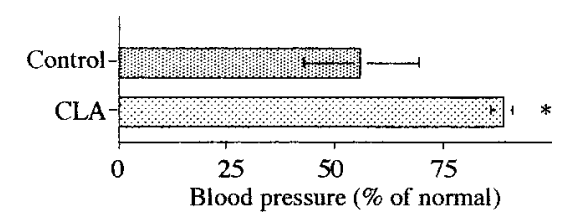

Fig. 1. Antianaphylactic Effect of CLA on Blood Pressure (BP)

HEL-sensitized mice were challenged with intravenous HEL, and BP was measured at 15-20 min after challenge. Control, without treatment (challenge only); CLA, pretreatment with CLA $(100 \mathrm{mg} / \mathrm{kg} / \mathrm{d}$ p.o. for 2 weeks). All values are mean percentages of normal BP \pm S.E. for 7 mice. $* p<0.05$ compared with control (Student's $t$-test).

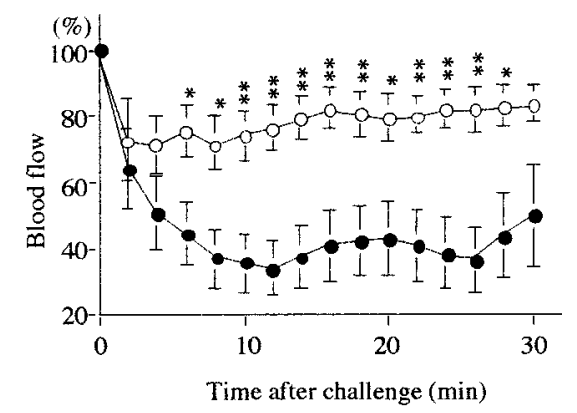

Fig. 2. Antianaphylactic Effect of CLA on Blood Flow (BF)

HEL-sensitized mice were challenged with intravenous HEL at $0 \mathrm{~min}$. $\bullet$, control; $\bigcirc$, pretreatment with CLA $(100 \mathrm{mg} / \mathrm{kg} / \mathrm{d}$ p.o. for 2 weeks $)$. All values are mean percentages of normal $\mathrm{BF} \pm \mathrm{S}$.E. for 7 mice. $* p<0.05$, $* * p<0.01$ compared with control (Student's $t$-test).

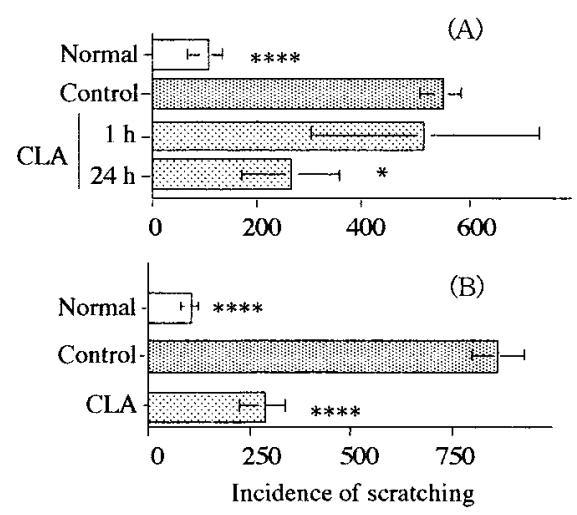

Fig. 3. Inhibitory Effect of CLA on Compound 48/80 (COM)-Induced Scratching Behavior

The bar labeled "control" refers to untreated mice injected with COM $3 \mathrm{mg} / \mathrm{kg}$ s.c. "Normal" shows the incidence of scratching behavior before injection with COM. (A) CLA was administered orally at a dose of $200 \mathrm{mg} / \mathrm{kg} 1 \mathrm{~h}$ or $24 \mathrm{~h}$ before with COM. The scratching behavior for the whole body was counted for $20 \mathrm{~min}$. (B) CLA $100 \mathrm{mg} / \mathrm{kg}$ was repeatedly administered orally once daily for 2 weeks before injection with COM. Each value represents the mean \pm S.E. of 5 or 7 mice. $* p<0.05$, **** $p<0.0001$ compared with control (Student's $t$-test).

the evoked scratching behavior. Figure $3 \mathrm{~B}$ shows that repetitive oral administration of CLA $(100 \mathrm{mg} / \mathrm{kg} / \mathrm{d})$ for 2 weeks very significantly inhibited COM-induced scratching behavior. When administered topically, CLA inhibited COM-induced scratching behavior in a dose-dependent manner (Fig. 4). A dose of $2.5 \mathrm{mg} / \mathrm{kg} / \mathrm{d}$ of CLA was significantly inhibited COM-induced scratching behavior. CLA mitigated PAF-induced (Fig. 5A) and PA-induced (Fig. 5B) scratching behavior. CLA alone did not affect scratching behavior in normal mice on all schedules or with all methods administration investigated.

\section{DISCUSSION}

We found that CLA has inhibitory effects against anaphy- 


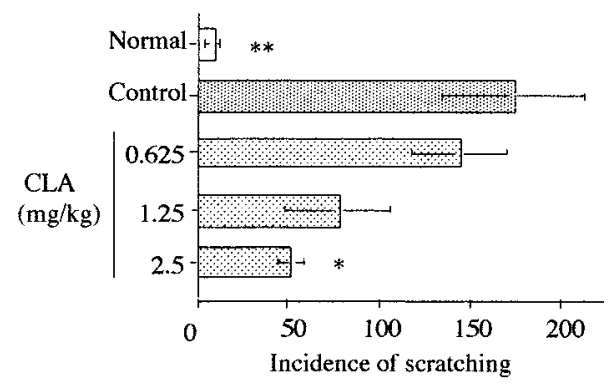

Fig. 4. Inhibitory Effect of CLA on COM-Induced Scratching Behavior

The bar labeled "control" refers to untreated mice injected with COM $3 \mathrm{mg} / \mathrm{kg}$ s.c. "Normal" shows the incidence of scratching behavior before injection with COM. CLA $0.625,1.25$, and $2.5 \mathrm{mg} / \mathrm{d}$ was repeatedly applied to the COM-injected site once daily for $5 \mathrm{~d}$ before injection with COM. The scratching behavior at the COM-injected site was counted for $20 \mathrm{~min}$. Each value represents the mean \pm S.E. of 5 mice. $* p<0.05$, $* * p<0.01$ compared with control (Student's $t$-test).
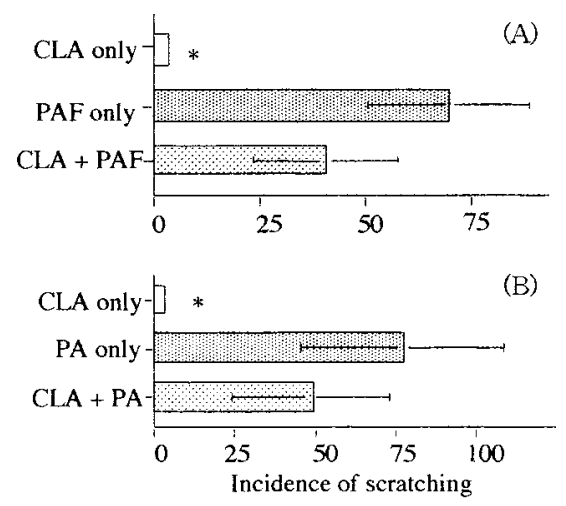

Fig. 5. Inhibitory Effect of CLA on PAF and Protease (PA)-Induced Scratching Behavior

PAF (A) $1 \mu \mathrm{g} / \mathrm{kg}$ s.c. or PA (B) $1 \mathrm{mg} / \mathrm{kg}$ s.c. was injected to provoke scratching. CLA $2.5 \mathrm{mg} / \mathrm{d}$ was repeatedly applied once daily for $5 \mathrm{~d}$ before injection with PAF or PA. The scratching behavior at the PAF- or PA-injected site was counted for $20 \mathrm{~min}$. Each value represents the mean \pm S.E. of 3 or 5 mice. $* p<0.05$ compared with control (Student's $t$ test).

laxis (type I hypersensitivity reactions). It significantly suppressed the decrease in BP (Fig. 1) and BF (Fig. 2) induced by the HEL-induced anaphylactic reaction. Decreasing the serum IgE concentration has been proposed as a method to suppress allergic reactions. A reduction in the $\operatorname{IgE}$ level of mensenteric lymph node lymphocytes in rat has been reported $^{16)}$ to occur with continual 3-week intake of CLA. However, CLA did not inhibit the anti-HEL IgE serum level in this model. Yamasaki et al. also reported that CLA did not affect the serum immunoglobulin level. ${ }^{21)}$ The major antianaphylactic mechanism of CLA, other than control of the serum IgE, is inhibition of the release ${ }^{14,15)}$ of chemical mediators and synthesis ${ }^{12)}$ of arachidonic acid metabolites.

CLA administered orally had antipruritic activity, since it significantly inhibited the scratching behavior (itch-associated response) induced by $\mathrm{COM}$, a histamine-releasing agent (Fig. 3A). The antipruritic activity of CLA increased with continual medication (Fig. 3B). When applied to the skin, CLA exhibited antipruritic activity (Fig. 4) and inhibited skin vasodilation induced by allergic mediators. These results suggest that CLA would be useful in treating allergic pruritus not only as an oral but also as a topical agent.

PAF and histamine are major mediators of pruritus. ${ }^{22,23)}$ CLA inhibited the pruritogenic action of PAF, because it in- hibited PAF-induced scratching behavior in mice (Fig. 5A). The antagonistic effect of CLA on PAF receptors should be studied in detail in the future. In atopic patients with severe pruritus in which antihistamine agents are not effective, PAF antagonistics may have a therapeutic effect. ${ }^{24)}$

Atopic dermatitis is a complex mixture of allergic and inflammatory reactions associated with severe pruritus. CLA decreases protease-induced scratching behavior in mice (Fig. 5B), and PA is known to be activated in inflammation tissue. CLA should therefore be useful for treating atopic dermatitis. To our knowledge, this is the first report of the antipruritic effect of CLA. CLA enhances the immune function of biological defense and suppresses superfluous immune function such as anaphylaxis. Thus CLA acts to maintain the homeostasis of immune system.

In summary, the present findings demonstrate that CLA can be effective for the prevention and treatment of an anaphylaxis and an allergic disease with severe pruritus.

\section{REFERENCES}

1) Kepler C. R., Hirons K. P., McNeill J. J., Tove S. B., J. Biol. Chem., 241, 1350-1354 (1966).

2) Pariza M. W., Hargraves W. A., Carcinogenesis, 6, 591-593 (1986).

3) Park Y., Albright K. J., Liu W., Storkson J. M., Cook M. E., Pariza M. W., Lipids, 32, 853-858 (1997).

4) Kohlmeier L., Simonsen N., Mottus K., Environ. Health Perspect., 8, 177-184 (1995).

5) Lee K. N., Kritchevsky D., Pariza M. W., Atherosclerosis, 108, 19-25 (1994).

6) Houseknecht K. L., Vanden Heuvel J. P., Moya-Camarena S. Y., Portocarrero C. P., Peck L. W., Nickel K. P., Belury M. A., Biochem. Biophys. Res. Commun., 244, 678-682 (1998).

7) Khosla P., Fungwe T. V., Curr. Opin. Lipidol., 12, 31-34 (2001).

8) Wong M. W., Chew B. P., Wong T. S., Hosick H. K., Boylston T. D., Shultz T. D., Anticancer Res., 17, 987-993 (1997).

9) Cook M. E., Miller C. C., Park Y., Pariza M. W., Poultry Sci., 72, 1301-1305 (1993).

10) Goodwin J. S., Webb D. A., Clin. Immunol. Immunopathol., 15, 106122 (1980).

11) Sugano M., Tsujita A., Yamasaki M., Noguchi M., Yamada K., Lipids, 33, 521-537 (1998).

12) Liu K. L., Belury M. A., Cancer Lett., 127, 15-22 (1998).

13) Watkins B. A. Seifert M. F., J. Am. Coll. Nutr., 19, 478s-486s (2000).

14) Akahoshi A., Goto Y., Murao K., Miyazaki T., Yamasaki M., Nonaka M., Yamada K., Sugano M., Biosci. Biotechnol. Biochem., 66, 916920 (2002).

15) Whigham L. D., Cook E. B., Stahl J. L., Saban R., Bjorling D. E., Pariza M. W., Cook M. E., Am. J. Physiol. Regul. Integr. Comp. Physiol., 280, 908-912 (2001).

16) Whigham L. D., Higbee A., Biorling D. E., Park Y., Pariza M. W., Cook M. E., Am. J. Physiol. Regul. Integr. Comp. Physiol., 282, 1104-1112 (2002).

17) Ishiguro K., Fukumoto H., Phythother. Res., 11, 48-50 (1997).

18) Ishiguro K., Ohira Y., Oku H., Biol. Pharm. Bull., 25, 505-508 (2002).

19) Ishiguro K., Oku H., Phythother. Res., 11, 343-347 (1997).

20) Fukumoto H., Yamaki M., Isoi K., Ishiguro K., Phythother. Res., 10, 202-206 (1996).

21) Yamasaki M., Kishihara K., Mansho K., Ogino Y., Kasai M., Sugano M., Tachibana H., Yamada Y., Biosci. Biotechnol. Biochem., 64, $2159-2164$ (2000).

22) Yamamoto S., Koro O., Hide M., Monthly Book Derma., 30, 25-33 (1999).

23) Oku H., Ishiguro K., Phythother. Res., 15, 506-510 (2001).

24) Abeck D., Andersson T., Grosshans E., Jablonska S., Kragballe K., Vahlquist A., Schmidt T., Dupuy P., Ring J., Acta Derm. Venereol., 77, 449-451 (1997). 